\title{
Development and Investigation of Diesel Fuel Reformer for LNT Regeneration
}

\author{
Thomas Wittka $^{1} \cdot$ Volker Müller $^{1} \cdot$ Peter Dittmann $^{1} \cdot$ Stefan Pischinger $^{1}$
}

Received: 10 March 2015 /Revised: 17 April 2015 / Accepted: 20 April 2015 / Published online: 9 May 2015

(C) Springer SIP, AG 2015

\begin{abstract}
In the present work, an exhaust after treatment system combining Lean $\mathrm{NO}_{\mathrm{X}}$ Trap (LNT) plus exhaust bypass, passive catalyst for selective catalytic reduction (SCR), and engine independent LNT reductant supply by on-board exhaust fuel reforming was developed. To demonstrate the mobile production of synthesis gas with focus on automotive application, an outline fuel reformer has been developed which is predominantly operated using engine exhaust gas. The reformer concept and design are described in detail. The reaction process is a variable superposition of exothermic catalyzed partial oxidation (CPOx) and endothermic steam (steam reforming (SR)) and $\mathrm{CO}_{2}$ (dry reforming (DR)) reformation. This strong dependence of the reformer operation on the engine's exhaust gas composition was intensively studied by steady-state experiments on an engine test bench. Besides operating the reformer within thermal limits, the control strategy is designed in terms of low hydrocarbon emissions and high energetic efficiency. In comparison to pure CPOx, exhaust gas reforming showed favorable thermal behavior as well as efficiency benefits of up to $20 \%$ due to the endothermic part of the reaction. The reformer could achieve a reductant yield of above $50 \%$, whereas only $10-25 \%$ for medium engine load and up to $45 \%$ for high engine load could be realized by engine-rich operation. For the investigated diesel engine-rich calibrations, the undesired $\mathrm{HC}$ emission reached a percentage share of the reductants of $15-55 \%$, whereas the reformer showed only up to $12 \%$.
\end{abstract}

Peter Dittmann

dittmann@vka.rwth-aachen.de

1 Institute for Combustion Engines, RWTH Aachen University, Aachen, Germany
Keywords Diesel reformer · Partial oxidation · Steam reforming $\cdot \mathrm{CO}_{2}$ reforming $\cdot$ Exhaust gas reforming $\cdot \mathrm{LNT}$

\section{Introduction}

Reforming of hydrocarbons to a hydrogen- $\left(\mathrm{H}_{2}\right)$ and carbon monoxide (CO)-rich reformate gas or synthesis gas is a wellestablished technology in the chemical industry. However, in mobile applications with strong restrictions, for example in terms of packaging, system complexity, and weight, the industrial fuel reformer technologies need to be scaled down and adapted. Further challenging requirements for automotive applications in comparison to stationary systems are a long lifetime without extensive maintenance, low costs, no or minimum refueling of second working fluid (e.g., water), highly dynamic operation, and a high number of cold starts.

Automotive fuel reforming could be used in different application areas. One possibility is the combustion of $\mathrm{H}_{2}$ and $\mathrm{CO}$ either thermally in a combustion engine or electrochemically in a fuel cell for vehicle propulsion. Besides, it can be used for electric power generation in an auxiliary power unit (APU), or $\mathrm{H}_{2}$ can be added to gasoline- or diesel-fueled combustion engines for enhancement of pollutant formation and fuel consumption [1-8]. Finally, it might be applied for after treatment issues as it is done in this investigation [9-18]. The diesel fuel reformer that is discussed in this paper is part of a combined Lean $\mathrm{NO}_{\mathrm{X}}$ Trap (LNT) + selective catalytic reduction (SCR) diesel exhaust after treatment system that was described in detail by the authors in a previous paper [19].

In general, in the reforming process, hydrocarbons get converted to a $\mathrm{H}_{2}$ - and $\mathrm{CO}$-rich synthesis gas by oxidation. The different reforming processes and reactions can be classified by the oxidizing agent $\left(\mathrm{O}_{2}, \mathrm{H}_{2} \mathrm{O}, \mathrm{CO}_{2}\right)$. An additional 
characterization consists of the energetic process and reaction behavior (endothermic or exothermic).

The catalyzed partial oxidation (CPOx) is an exothermic reforming reaction and is based on molecular $\mathrm{O}_{2}$. The strong understoichiometric reaction (air/fuel ratio $\lambda \approx 0.34$ ) is usually adiabatically operated at $700-1,000{ }^{\circ} \mathrm{C}[20]$. The $\lambda$ operation range is narrow. Low $\lambda$ values $(<0.34)$ are critical due to soot and methane formation. High $\lambda$ values $(>0.39)$ are critical due to exothermic temperature increase. In comparison to the endothermic reforming processes, the complexity of CPOx is low. On the one hand, the exothermic character is advantageous. No complex energy supply is necessary, and the process can be operated very dynamically. However, the high system temperature requires thermal stable catalysts and a very accurate operation control. In addition, an air supply is necessary.

By the endothermic steam reforming (SR), the hydrocarbon conversion takes place with $\mathrm{H}_{2} \mathrm{O}$ and is operated at 750 $900{ }^{\circ} \mathrm{C}[20]$. Considerable energy needs to be supplied to operate the reaction and to vaporize $\mathrm{H}_{2} \mathrm{O}$. Therefore, $\mathrm{SR}$ is a complex technology for automotive application. The reaction enthalpy needs to be generated, for example by fuel combustion, and transferred to the reactants or to the catalyst by heat exchangers. This results in a low dynamic load change. Additionally, a closed $\mathrm{H}_{2} \mathrm{O}$ circulation, including for example tank and vaporizer, is necessary. This leads to a high system complexity, package, and weight.

A second endothermic reforming process is the $\mathrm{CO}_{2}$ or dry reforming (DR) that takes place with $\mathrm{CO}_{2}$. To avoid soot formation, DR needs to be operated $>900{ }^{\circ} \mathrm{C}$ [20]. In comparison to SR, DR has less technical relevance up to now. Nevertheless, it is a possible reaction pathway for reforming with $\mathrm{CO}_{2}$ containing exhaust gas or of $\mathrm{CO}_{2}$-containing natural gas and bio gas.

A combination of exothermic and endothermic reactions is advantageous for the reforming process control. The autothermal reforming (ATR) is in ideal case energetically neutral. Oxidative steam reforming (net endothermic) and steam-supported partial oxidation (net exothermic) are intermediate stages. Fuel reforming with variable exhaust gas can represent all energetic stages. In autothermal and net exothermic reactors, the required reaction enthalpy of the endothermic reactions can be supplied by the exothermic reactions inside the reactor without complex heat exchange components. Hence, the system can be designed compactly and operated dynamically. Additionally, the critical high reaction temperature of the CPOx can be reduced and damped by endothermic heat consumption. Pure combination of SR and $\mathrm{CPOx}$ still requires water and air supply. In contrast, using $\mathrm{O}_{2-}, \mathrm{H}_{2} \mathrm{O}$-, and $\mathrm{CO}_{2}$-containing exhaust gas from a combustion engine offers potential to reduce the supply systems of additional working fluids. Summarizing, exhaust gas-based reforming offers potential to design a compact and dynamic reactor with advantages in terms of thermal behavior as well as energetic efficiency.

\section{Description of Reformer Concept and Layout}

The outline on-board fuel reformer as part of the combined LNT + SCR after treatment system is predominantly operated by exhaust gas, which is taken downstream diesel particulate filter (DPF) (the LNT + SCR combination is positioned downstream DPF, detailed system description in [19]). In general, three different concepts for reactant mixing upstream reforming catalyst can be distinguished. In the first type, the reactant mixing processes have no thermal interaction with the hot reforming zone (for example, the CPOx reactor in [21]). The second type is a coaxial design with reforming catalyst in the inner part and flow of fresh air or exhaust gas around the catalyst. By this, the reactant mixing processes are thermally interacting with the hot reforming zone (for example, the CPOx reactor in $[15,22])$. The third type is also a coaxial design but with a ring-shaped reforming catalyst and flow of fresh air or exhaust gas along the inner walls of the catalyst. This concept also offers high potential of thermal interaction of the reactant mixing processes and the hot reforming zone. Similar concepts are described in [23] and [24]. The developed on-board fuel reformer is a coaxial design according type 3 and shown in detail in Fig. 1. Diesel is injected into the reformer mixing chamber by a serial air-assisted, lowpressure injector ( 5 bar fuel injection pressure, 1 bar air pressure $)$ at a significant understoichiometric air/fuel ratio $\left(\lambda_{\mathrm{Ref}}=\right.$ $0.35-0.80)$ and is catalyzed to a $\mathrm{H}_{2-}$ and $\mathrm{CO}$-rich synthesis gas.

The reaction enthalpy, which is released in the ring-shaped reformer catalyst, supports fuel vaporization via internal heat transfer. The reforming reaction process can be described by superposition of exothermic CPOx by the residual oxygen in the exhaust gas as well as the secondary air and endothermic SR and DR which occurs via $\mathrm{H}_{2} \mathrm{O}$ and $\mathrm{CO}_{2}$ introduced by the exhaust gas. Moreover, the reforming products are temperature dependently in chemical equilibrium, among others mainly according to the water gas shift (WGS) and methanation reaction.

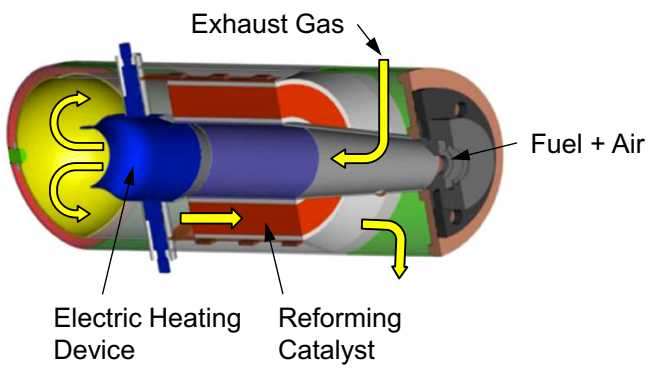

Fig. 1 CAD design of the fuel reformer 
The electric heating device is only activated during cold start. As soon as the reformer catalyst is heated up to a temperature of $250-300{ }^{\circ} \mathrm{C}$, the heating device is switched off and the proceeding of heating up takes place by lean oxidation of small diesel injections on the reformer catalyst. Because of the outline position, the reformer does not cool down fast during low engine load operation. Hence, the electrical-supported reformer cold start is only necessary after long break intervals with engine off.

\section{Investigation Methodology}

\subsection{Theoretical}

\subsubsection{Chemical Equilibrium Calculations}

The theoretical study of the thermochemistry of the exhaust gas reforming was done with a commercially available chemical reaction and equilibrium software [25]. The applied diesel fuel was defined according the composition from [26] and implemented in the software. Missing fuel species in the base library were implemented manually with data sets from [27]. The applied diesel fuel composition results in a theoretical hydrocarbon species $\mathrm{C}_{12.93} \mathrm{H}_{24.40}$. The exhaust gas composition (residual $\mathrm{O}_{2}, \mathrm{H}_{2} \mathrm{O}, \mathrm{CO}_{2}, \mathrm{~N}_{2}$ ) and the corresponding air/fuel ratio $\lambda$ were calculated according to the reaction equations. The equilibrium determination was conducted for the following gas matrix: diesel (all single species from [26]), $\mathrm{H}_{2} \mathrm{O}, \mathrm{O}_{2}, \mathrm{H}_{2}, \mathrm{CO}_{2}, \mathrm{CO}, \mathrm{CH}_{4}$, and $\mathrm{C}$.

\subsubsection{Definition of Reforming Parameters}

Due to the strong $\lambda$ dependence of the exhaust gas composition of the real engine, the energetic reforming condition (exothermic for high residual oxygen in very lean exhaust gas, endothermic for $\lambda$ close to 1 ) is strongly variable. In order to describe the reforming condition, three standardized parameters were defined beside conventional parameters like temperature and space velocity. The first parameter $r_{\text {Exhaust }}$ is the ratio of the exhaust gas molar flow to the sum of exhaust gas and secondary air molar flows in the reformer (Eq. 1). This parameter is an indicator for the secondary air portion in the reformer inlet gas flows. The second parameter $\lambda$ of the reformate gas and of the input gas flows is calculated according to Eq. $2(O$ is number of oxygen atoms in all exhaust components, $C$ is number of carbon atoms in all exhaust components, $H$ is number of hydrogen atoms in all exhaust components). The third parameter $r_{\mathrm{POx}}$ is the main indicator of the exhaust gas reforming process (Eq. 3). It describes the fraction of the molar oxygen source to the total amount of all oxygen sources for the reforming reactions $\left(\mathrm{O}_{2}, \mathrm{H}_{2} \mathrm{O}\right.$, and $\left.\mathrm{CO}_{2}\right) \cdot r_{\mathrm{POx}}=1$ is pure CPOx (maximum exothermic) and $r_{\mathrm{POx}}=0$ is pure SR + DR (maximum endothermic). It can either be calculated by the molar flows or by the reforming reaction characterization parameters $S / C, C / C$, and $O / C$ (Eqs. 4-6) that are derived from the stoichiometric coefficients of the reforming reaction equations (Eqs. 7-9). The theoretical and experimental results are discussed based on these parameters.

$r_{\text {Exhaust }}=\frac{\dot{n_{\text {Exhaust }}}}{\dot{n}_{\text {Exhaust }}+\dot{n}_{\text {Air }}}$

$\lambda=\frac{\sum n_{O}}{2 \cdot \sum n_{C}+0.5 \cdot \sum n_{H}}$

$r_{P O x}=\frac{2 \cdot \dot{n}_{O_{2}}}{2 \cdot \dot{n}_{\mathrm{O}_{2}}+\dot{n}_{\mathrm{H}_{2} \mathrm{O}}+\dot{n}_{\mathrm{CO}_{2}}}$ or $\frac{O / C}{\mathrm{O} / \mathrm{C}+S / \mathrm{C}+\mathrm{C} / \mathrm{C}}$

$S / C=\frac{\dot{n_{H_{2} \mathrm{O}}}}{12.93 \cdot \dot{n}_{\text {Diesel }}}$

$C / C=\frac{\dot{n_{\mathrm{CO}_{2}}}}{12.93 \cdot \dot{n}_{\text {Diesel }}}$

$O / C=\frac{2 \cdot \dot{n}_{O_{2}}}{12.93 \cdot \dot{n}_{\text {Diesel }}}$

$\mathrm{C}_{x} \mathrm{H}_{y}+x \mathrm{H}_{2} \mathrm{O} \rightleftarrows x \mathrm{CO}+\left(\mathrm{x}+\frac{y}{2}\right) \mathrm{H}_{2}$

$$
\Delta_{R} \mathrm{H}_{298}^{0}=+1,911 \frac{k J}{\text { mol }_{\mathrm{C}_{12.93} \mathrm{H}_{24,40}}}
$$

$\mathrm{C}_{x} \mathrm{H}_{y}+x \mathrm{CO}_{2} \rightleftarrows 2 x \mathrm{CO}+\frac{y}{2} \mathrm{H}_{2}$

$$
\Delta_{R} H_{298}^{0}=+2,442 \frac{k J}{m_{C_{12.93} H_{24.40}}}
$$

$$
\begin{gathered}
C_{x} H_{y}+\frac{1}{2} x O_{2} \rightleftarrows x C O+\frac{y}{2} H_{2} \\
\Delta_{R} H_{298}^{0}=-1,215 \frac{\mathrm{kJ}}{\mathrm{mol}_{\mathrm{C}_{12.93} H_{24.40}}}
\end{gathered}
$$

\subsection{Experimental}

\subsubsection{Catalyst Preparation}

The reformer catalyst is ring-shaped and based on ceramic substrate with a PGM load of $60 \mathrm{~g} / \mathrm{ft}^{3}(0 / 0 / 1 \mathrm{Pt} / \mathrm{Pd} / \mathrm{Rh})$ and a volume of $0.5 \mathrm{~L}$ (company CCD GbR). The cell density of the reforming substrate is $600 \mathrm{cpsi}$. The reforming catalyst was not initially thermally aged but did not show any degradation in reference points during the experimental investigation period. 


\subsubsection{Engine Test Bench Experiments}

The full-scale experiments for investigating the performance of the fuel reformer were conducted with a diesel engine on a transient engine test bench. The control logic of the reformer was running on a rapid control prototyping system (ES1000 Fa. ETAS). Communication between engine and reformer control was done via ECU bypass. The emissions were measured by different analyzers (chemiluminescence detection (CLD): $\mathrm{NO}_{\mathrm{X}}, \mathrm{NO}$; non-dispersive infrared spectrometry (NDIR): $\mathrm{CO}, \mathrm{CO}_{2}$; Magnos $\mathrm{O}_{2}$ detection: $\mathrm{O}_{2}$; flame ionization detection (FID): total hydrocarbons (THC); Fourier transformation infrared spectrometry (FTIR): $\mathrm{NO}, \mathrm{NO}_{2}, \mathrm{CO}, \mathrm{CO}_{2}$, $\mathrm{H}_{2} \mathrm{O}, \mathrm{NH}_{3}, \mathrm{~N}_{2} \mathrm{O}, \mathrm{CH}_{4}, \mathrm{SO}_{2}$; process mass spectrometer (PrMS): $\left.\mathrm{H}_{2}, \mathrm{H}_{2} \mathrm{~S}, \mathrm{SO}_{2}, \mathrm{COS}, \mathrm{CS}_{2}\right)$ and sensors $\left(\mathrm{NO}_{\mathrm{X}}, \lambda\right)$ at various positions (engine out, downstream of the DPF, end of pipe). CLD, NDIR, FID, and Magnos were combined in one exhaust analyzer system (AMA). The PrMS is an analytical unit constructed by V\&F including the TWIN-MS (CIMS with soft ionization by source gases: $\mathrm{Xe}, \mathrm{Kr}, \mathrm{Hg}$ ) and the $\mathrm{H}$ Sense (EI with ionization by ion beam), which allows to detect all data parallel in lifetime with a very high dynamic $(30 \mathrm{~ms}$ for each substance). The gas composition of the outline exhaust gas fuel reformer was not measured directly in the reformate gas but calculated based on emission measurements in the full exhaust gas flow and the according dilution factor. The diluted measurement was chosen in order to avoid HC concentrations on high level and avoid measurement device errors. The thermocouples in the reformer catalyst have a diameter of $0.5 \mathrm{~mm}$. The total after treatment system was setup very modularly. For the reformer measurements, the LNT (original position in the upper exhaust bypass) and the SCR (original position downstream the mixer unit) catalyst units were replaced by empty exhaust pipes. A schematic overview of the experimental setup on the engine test bench is given in Fig. 2.

\section{Results and Discussion}

\subsection{Theoretical Study of Thermochemistry}

A theoretical study of the thermochemistry was conducted in order to investigate the boundary conditions of the fuel reforming on base of highly variable exhaust gas composition. Furthermore, the definition of the control strategy is based on these considerations.

The core parameter of the exhaust gas reforming is the variable exhaust gas composition. For low $\lambda_{\text {Engine }}$ close to 1 with very low residual $\mathrm{O}_{2}$, e.g., during high engine load, the reaction conditions in a purely exhaust gas-based reformer are very endothermic ( $r_{\mathrm{POx}}$ close to 0$)$. The reformer operation under these conditions requires either high exhaust temperatures or a very high $\lambda_{\text {Ref }}$ in order to supply the necessary
Fig. 2 Schematic experimental setup on engine test bench: overview of exhaust gas analyzers, sensors, actuators, and rapid prototyping control

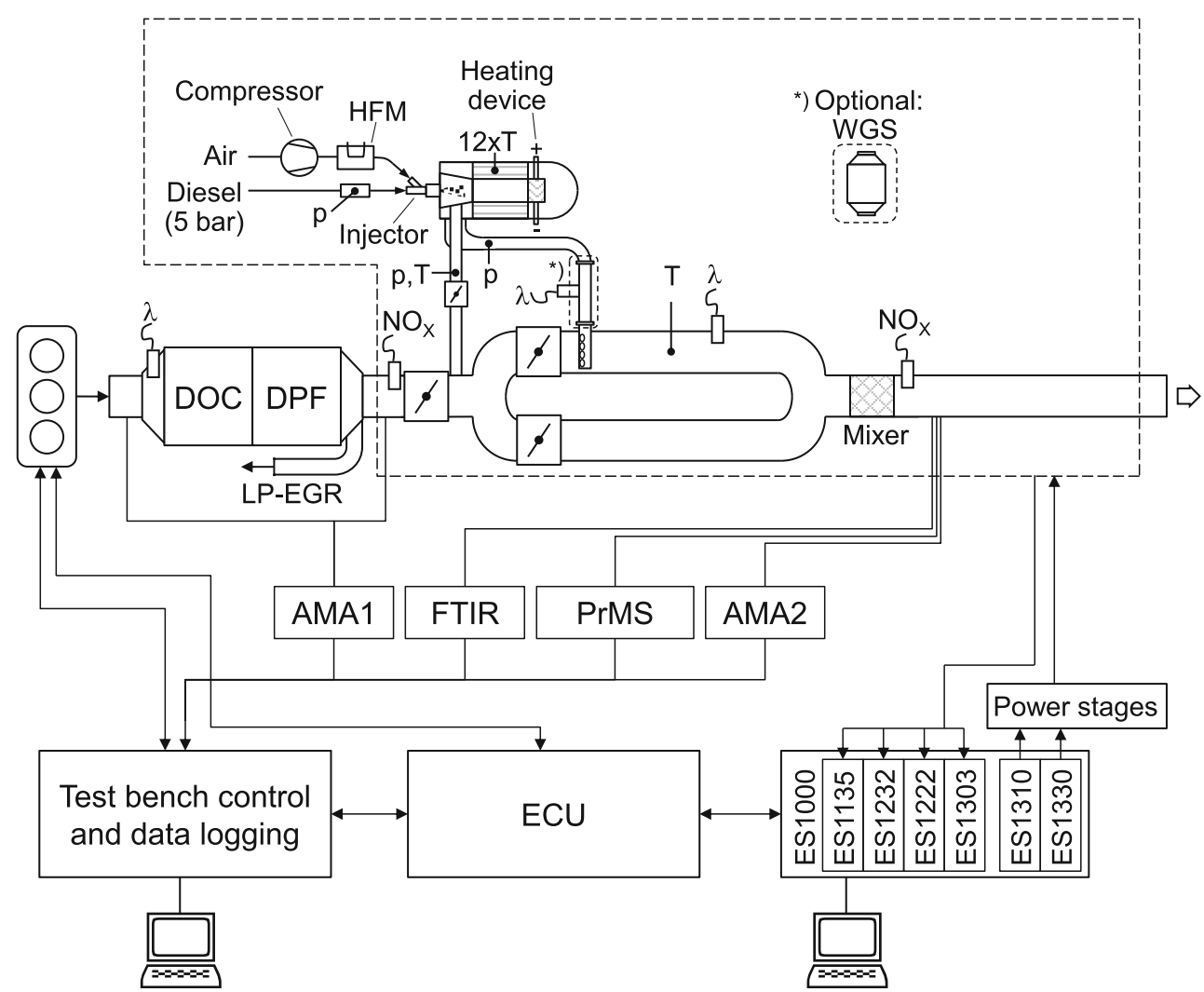


reaction enthalpy to the reformer. In contrast, during low engine load or in extreme case during engine overrun with high residual $\mathrm{O}_{2}$ and only minor $\mathrm{H}_{2} \mathrm{O}$ and $\mathrm{CO}_{2}$, the reaction conditions are very exothermic $\left(r_{\mathrm{POx}}\right.$ close to 1). Under these conditions, the reformer operation is critical in case of high exhaust gas temperatures. Figure 3 shows the theoretically required $\lambda_{\text {Ref }}$ for an adiabatic exhaust gas reformer in order to achieve, for example, a reformer temperature of $900{ }^{\circ} \mathrm{C}$ as function of $\lambda_{\text {Engine }}$ for two different $T_{\text {Exhaust }}$. As an example, the left diagram shows an outline reformer with low $T_{\text {Exhaust }}$, whereas the right diagram shows an in-line reformer with high $T_{\text {Exhaust. }}$ Additionally, the reductant formation yield $\left(Y_{\text {Red }}\right)$ as an important indicator in terms of energetic efficiency is shown. $Y_{\text {Red }}$ is defined as ratio of oxygen consumption potential of the reducing agent available in the exhaust gas relative to the additional fuel introduced to reach rich operation. It can generally be calculated by Eq. 10 .

$Y_{\mathrm{Red}}=\frac{\dot{n}_{\mathrm{H}_{2}}+\dot{n}_{\mathrm{CO}}+\left(2 x+\frac{y}{2}\right) \cdot \dot{n}_{\mathrm{C}_{x} \mathrm{H}_{y}}-2 \cdot \dot{n}_{\mathrm{O}_{2}}-\dot{n}_{\mathrm{NO}}-2 \cdot \dot{n}_{\mathrm{NO}_{2}}}{\left(2 x+\frac{y}{2}\right) \cdot \dot{n}_{C_{x} H_{y}, \text { Diesel }}}$

For low $\lambda_{\text {Engine, }} \lambda_{\text {Ref }}$ needs to be enleaned up to 1 in order to achieve the target reformer temperature. $Y_{\text {Red }}$ is zero and hence this operation range is, besides heating up, not practically useful (zone I). The higher the $\lambda_{\text {Engine, }}$, the lower must be $\lambda_{\text {Ref }}$ to keep the target reformer temperature. For high $T_{\text {Exhaust }}$ and $\lambda_{\text {Engine }}$, the required $\lambda_{\text {Ref }}$ reaches the minimum $\left(\lambda_{\text {Ref,min }}\right)$. Below $\lambda_{\text {Ref,min, }}$, soot formation and considerable HC slip will occur. Thus, this operation range is not useful (zone III). Summarizing, high $T_{\text {Exhaust }}$ are advantageous for low $\lambda_{\text {Engine }}$. However, the useable $\lambda_{\text {Engine }}$ operation range is limited. An outline positioned reformer in combination with a secondary air supply for low $\lambda_{\text {Engine }}$ offers the best potential.

The complete operating limits and the possible $\lambda_{\text {Ref }}$ operation range for adiabatic exhaust gas reforming assuming chemical equilibrium as function of $r_{\mathrm{POx}}$ are shown in Fig. 4. The operating range is defined by four limits ((1) maximum $T_{\text {Ref, }}$ (2) start of soot formation, (3) minimum $T_{\text {Ref }}$ for minimum reaction rate and avoidance of methanation, (4) $\lambda_{\text {Ref,min }}$ ).

For decreasing $r_{\text {POx }}, \lambda_{\text {Ref }}$ needs to be increased to keep the reformer within the limits. The $\lambda_{\text {Ref }}$ operation range gets wider and is less sensitive to inaccuracies in the reformer control. Moreover, the soot formation limit is less critical. In contrast, for high $r_{\mathrm{POx}}$, the operation range is very narrow and close to the soot formation and stoichiometric limits. Hence, low $r_{\mathrm{POx}}$ are advantageous.

\subsection{Steady-State Reforming Measurements}

The reforming operation was investigated in terms of maximizing the system efficiency and minimizing $\mathrm{HC}$ and $\mathrm{CH}_{4}$ emission while complying with the maximum temperature limit. For the efficiency evaluation, two parameters were assessed. The reductant formation yield $Y_{\text {Red }}$ (due to low activity, $\mathrm{HC}$ is not considered for this evaluation) is most relevant for LNT regeneration. The ratio of the lower heating values of the products and the injected diesel fuel (heating value ratio (HVR)) is only relevant for heating up processes, for example for DPF regeneration or LNT heat-up but less relevant for LNT regeneration (Eq. 11). The $C$-equivalent HC conversion is calculated by Eq. 12 .

$$
\begin{aligned}
& H V R=\frac{H_{H_{2}} \cdot \dot{m}_{H_{2}, \mathrm{Re} f}+H_{C O} \cdot \dot{m}_{C O, \operatorname{Re} f}+H_{H C} \cdot \dot{m}_{H C, \mathrm{Ref}}}{H_{\text {Diesel }} \cdot \dot{m}_{\text {Diesel }}} \\
& \eta_{H C}=1-\frac{x \cdot \dot{n}_{H C_{X, \text { Ref }}}}{12.93 \cdot \dot{n}_{\text {Diesel }}}
\end{aligned}
$$

The influence of $\lambda_{\text {Ref }}$ on the reformate gas composition, temperature, and the efficiency indicators is shown in Fig. 5 (as example for $\lambda_{\text {Engine }}=2.05, r_{\mathrm{POx}}=0.70, r_{\text {Exhaust }}=0.8$, $\mathrm{SV}_{\text {Ref }}=9,000 \mathrm{~h}^{-1}$, and $T_{\text {Exhaust }} \approx 200^{\circ} \mathrm{C}$ ).

With increasing $\lambda_{\text {Ref }}$, the $\mathrm{HC}$ conversion is steadily increasing and reaches full conversion for $\lambda_{\text {Ref }}=0.55$. Maximum $\lambda_{\text {Ref }}$
Fig. 3 Theoretically required $\lambda_{\text {Ref }}$ for adiabatic exhaust gas reforming in order to achieve a reformer temperature of $900{ }^{\circ} \mathrm{C}$ (as example) and the corresponding reductant yield $Y_{\text {Red }}$ in chemical equilibrium as function of $\lambda_{\text {Engine: }}$ a $T_{\text {Exhaust }}=$ $100{ }^{\circ} \mathrm{C}$, b $T_{\text {Exhaust }}=600{ }^{\circ} \mathrm{C}$; zone II: useable $\lambda$ operation range, zone I, III: not useable $\lambda$ operation range $\left(T_{\text {Diesel }}=25^{\circ} \mathrm{C}\right)$ (a)

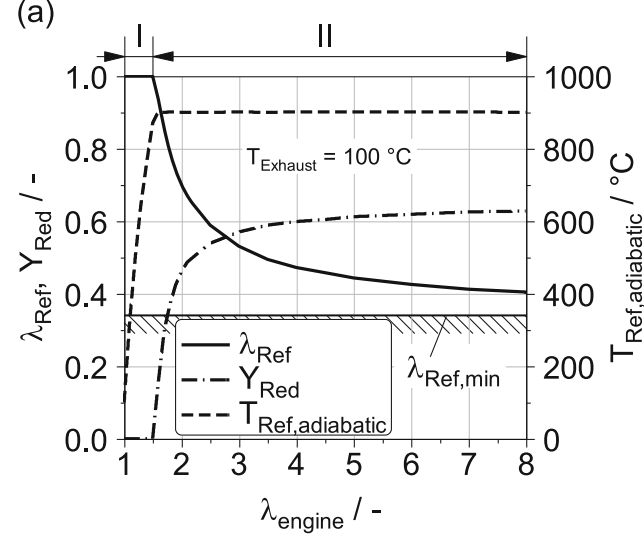

(b)

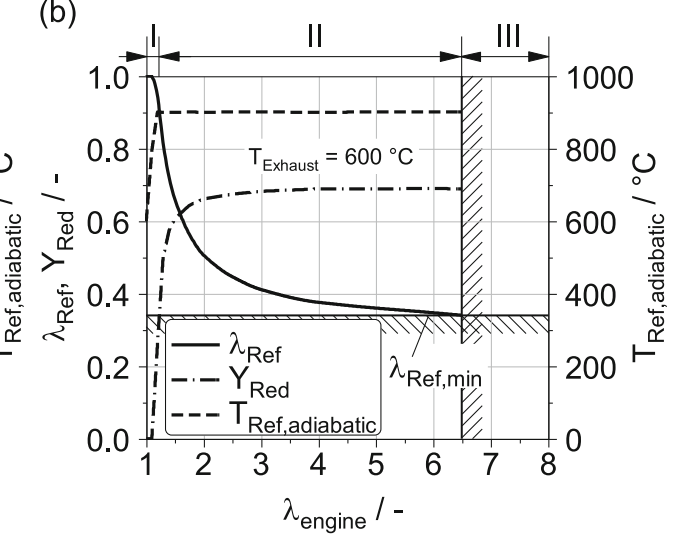


Fig. 4 Possible $\lambda_{\text {Ref }}$ operation range for adiabatic exhaust gas reforming in chemical equilibrium as function of $r_{\mathrm{POx}}$ ( $\lambda_{\text {Engine }}$ as example for $r_{\text {Exhaust }}=$ $0.8)\left(r_{\text {Exhaust }}=0.8, T_{\text {Exhaust }}=\right.$ $250{ }^{\circ} \mathrm{C}, T_{\text {Air }}=25^{\circ} \mathrm{C}, T_{\text {Diesel }}=$ $25^{\circ} \mathrm{C}$ )

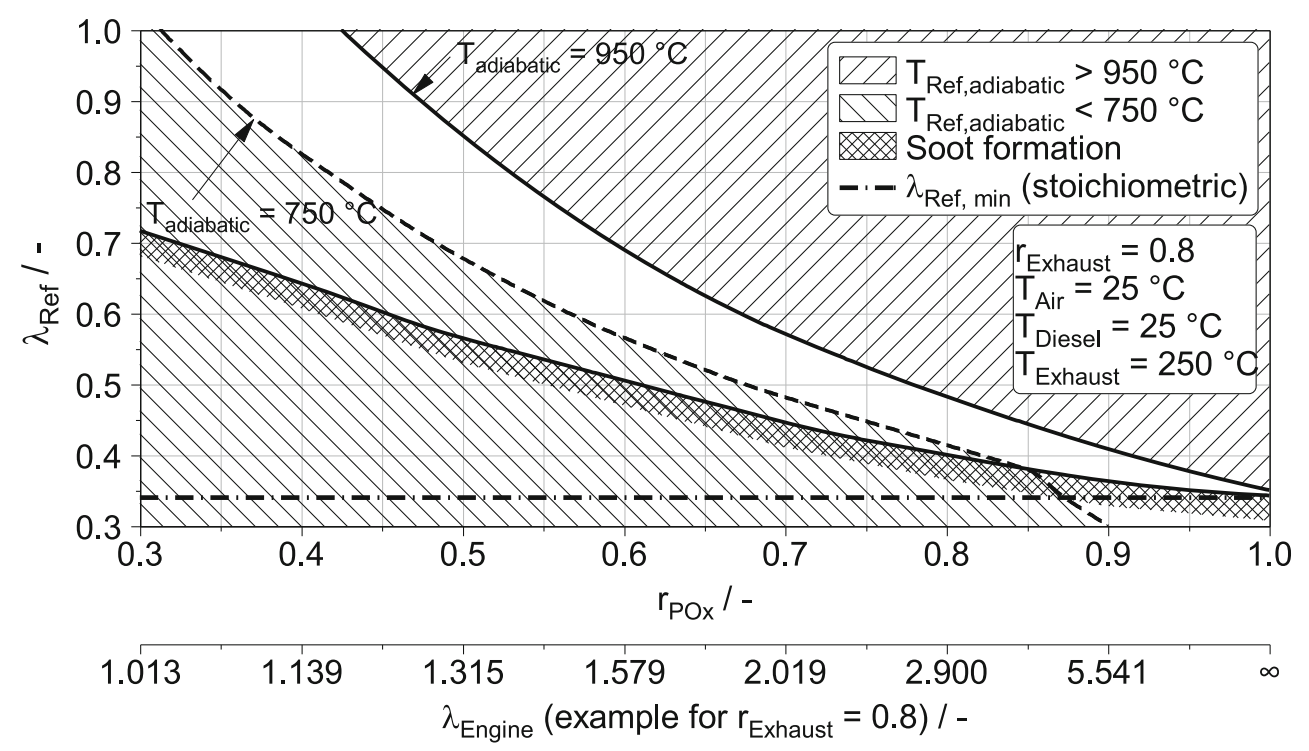

is defined by the maximum temperature. The methane emission for low $\lambda_{\text {Ref }}$ can be explained either by incomplete $\mathrm{HC}$ conversion or by the methanation reaction due to low temperatures. The reductant yield reaches a maximum at $\lambda_{\text {Ref }}=0.45$. $Y_{\text {Red }}$ decreases for lower $\lambda_{\text {Ref }}$ because of incomplete $\mathrm{HC}$ conversion and for higher $\lambda_{\text {Ref }}$ due to total oxidation reactions to the products $\mathrm{H}_{2} \mathrm{O}$ and $\mathrm{CO}_{2}$. For this example, the optimum $\lambda_{\text {Ref }}$ is 0.525 as best compromise of minimum nonmethane hydrocarbons (NMHC) and $\mathrm{CH}_{4}$ emissions and maximum $Y_{\text {Red }}$ while complying with the maximum temperature limit.

The influence of $r_{\mathrm{POx}}$ on the reformate gas composition, temperature, and the efficiency indicators is shown in Fig. 6 (as example for $r_{\text {Exhaust }}=0.8, \mathrm{SV}_{\mathrm{Ref}}=9,000 \mathrm{~h}^{-1}$, and $T_{\text {Exhaust }} \approx 200{ }^{\circ} \mathrm{C}$ ). $\lambda_{\text {Engine }}$ is variable. $\lambda_{\text {Ref }}$ needs to be adapted to keep the other boundary conditions constant and the $\mathrm{HC}$ emission low.

For high $\lambda_{\text {Engine }}$ and hence high $r_{\mathrm{POx}}$ with predominantly exothermic conditions, $\lambda_{\text {Ref }}$ needs to be low in order to comply with the maximum temperature. However, this results in increased $\mathrm{HC}$ emissions. For lower $\lambda_{\text {Engine }}$ and hence lower $r_{\text {POx }}$, $\lambda_{\text {Ref }}$ needs to be enleaned to avoid reformer cool down and HC emission. For low $r_{\mathrm{POx}}$, even for lower temperatures, the $\mathrm{HC}$ emission is zero. The optimum operation point with a maximum $Y_{\text {Red }}$ is $r_{\mathrm{POx}}=0.70 . Y_{\text {Red }}$ decreases for lower $r_{\mathrm{POx}}$ because of increased $\lambda_{\text {Ref }}$ and for higher $r_{\text {POx }}$ due to incomplete HC conversion. For very low $r_{\mathrm{POx}}$ with high $\mathrm{H}_{2} \mathrm{O}$ concentrations, $\mathrm{H}_{2}$ increases caused by WGS on the reformer outlet.
Fig. 5 Measured reformate gas composition and reforming catalyst temperature as function of $\lambda_{\text {Ref }}\left(\lambda_{\text {Engine }}=2.05, r_{\mathrm{POx}}=0.70\right.$, $r_{\text {Exhaust }}=0.8, \mathrm{SV}_{\mathrm{Ref}}=9,000 \mathrm{~h}^{-1}$, $T_{\text {Exhaust }} \approx 200{ }^{\circ} \mathrm{C}$ )

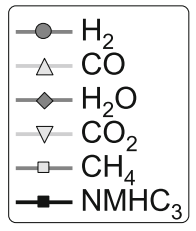

(a)

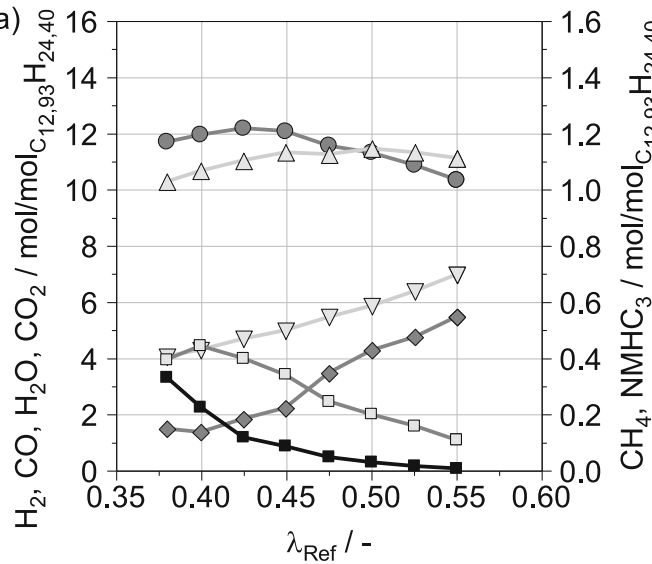

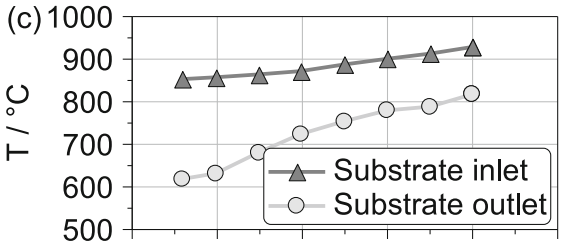

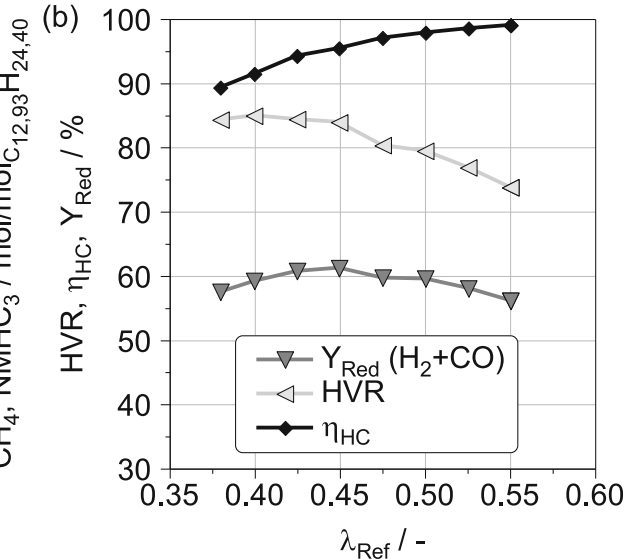


Fig. 6 Measured reformate gas composition and reforming catalyst temperature as function of $r_{\text {POx }}\left(\lambda_{\text {Engine variable, }} \lambda_{\text {Ref }}\right.$ variable, $r_{\text {Exhaust }}=0.8, \mathrm{SV}_{\mathrm{Ref}}=$ $9,000 \mathrm{~h}^{-1}, T_{\text {Exhaust }} \approx 200^{\circ} \mathrm{C}$ )
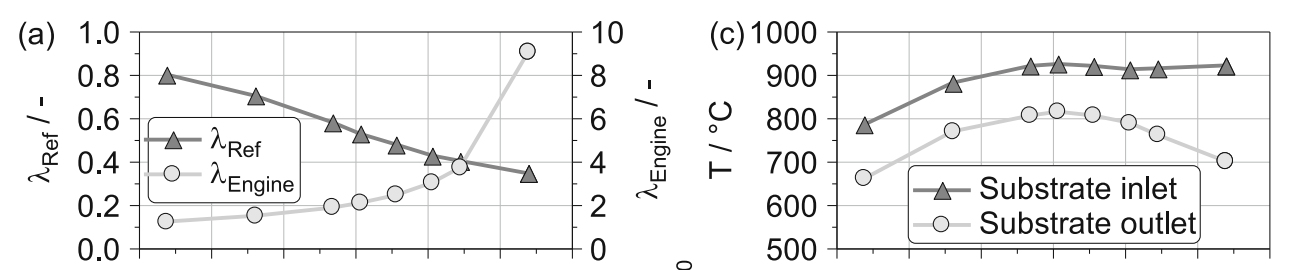

(b)

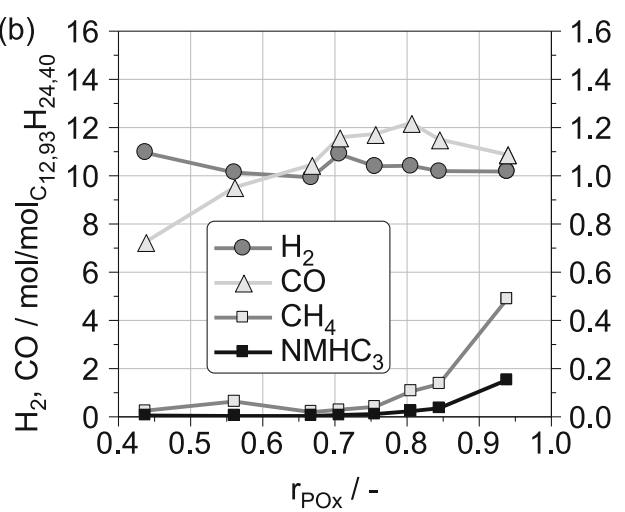

(d)

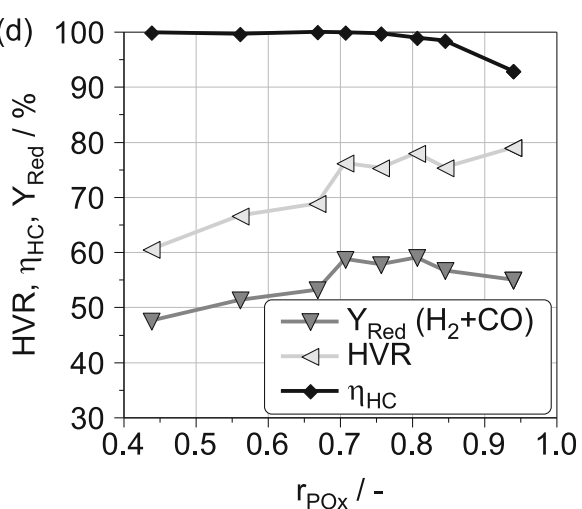

Finally, the influence of the reformer space velocity $\mathrm{SV}_{\mathrm{Ref}}$ on the reformate gas composition, temperature, and the efficiency indicators is shown in Fig. 7 (as example for $r_{\mathrm{POx}}=0.70$ and $T_{\text {Exhaust }} \approx 200{ }^{\circ} \mathrm{C}$ ). $\lambda_{\text {Ref }}$ and $r_{\text {Exhaust }}$ need to be adapted to keep the other boundary conditions constant and the HC emission low.

The relative heat losses increase with decreasing $\mathrm{SV}_{\text {Ref. }}$. To avoid lower reformer temperature and $\mathrm{HC}$ emissions, $\lambda_{\text {Ref }}$ needs to be increased. This results in lower $Y_{\text {Red. }}$. At high $\mathrm{SV}_{\mathrm{Ref}}$, $\mathrm{HC}$ emissions cannot be avoided for this operation point $\left(r_{\mathrm{POx}}=0.70\right)$. The higher temperature difference between substrate inlet and outlet is an indication for different axial reaction zones (the fast CPOx occurs on the inlet, the slower SR and DR occur on the outlet). To keep the temperature of the substrate inlet below the limit, low $\lambda_{\text {Ref }}$ is necessary and results in $\mathrm{HC}$ emissions. For lower $r_{\mathrm{POx}}\left(\right.$ not shown), higher $\mathrm{SV}_{\text {Ref }}$ can be managed without $\mathrm{HC}$ emission. For this operation point, the optimum $\mathrm{SV}_{\mathrm{Ref}}$ is $\approx 10,000 \mathrm{~h}^{-1}$ with $\lambda_{\mathrm{Ref}}=0.5$. This represents a thermal power of $10 \mathrm{~kW}_{\text {th }}$ (considering the lower heating value of the injected diesel).

Summarizing, for all optimized reforming operation points, the reformate gas composition and the efficiency indicators are shown as function of $\lambda_{\text {Ref }}$ in Fig. 8. The left diagram shows a comparison of the $\mathrm{H}_{2}$ and $\mathrm{CO}$ molar concentrations achieved under steady-state conditions with those attainable at stoichiometric conditions. The concentrations are close to the maximum yield and demonstrate high fuel conversion. In addition, the rich exhaust gas composition of a rich diesel engine operation is shown. Compared to the rich diesel engine operation,
Fig. 7 Measured reformate gas composition and reforming catalyst temperature as function of $\mathrm{SV}_{\text {Ref }}\left(\lambda_{\text {Engine }}\right.$ variable, $\lambda_{\text {Ref }}$ variable, $r_{\text {Exhaust }}$ variable, $r_{\mathrm{POx}}=$ $0.70, T_{\text {Exhaust }} \approx 200^{\circ} \mathrm{C}$ )
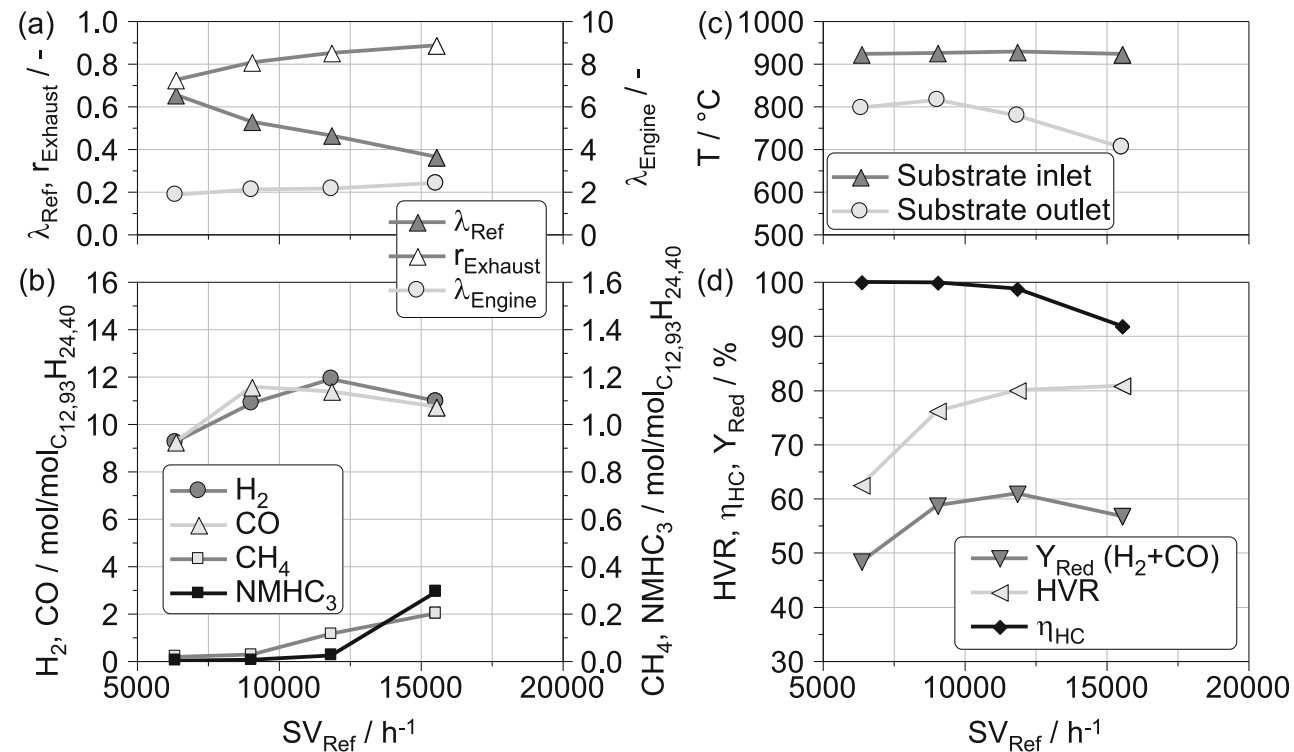
Fig. 8 Reformer output as function of reformer air/fuel ratio for optimized reformer operation: a Measured and theoretical $\mathrm{H}_{2}$ and $\mathrm{CO}$ molar concentrations in reformate. b Measured and theoretical CPOx values for ratio of heating values (HVR) and reductant yield ( $Y_{\text {Red }}$, only $\mathrm{H}_{2}+$ $\mathrm{CO}$ considered) of the reformer, engine air/fuel ratio of the exhaust gas supply to the reformer

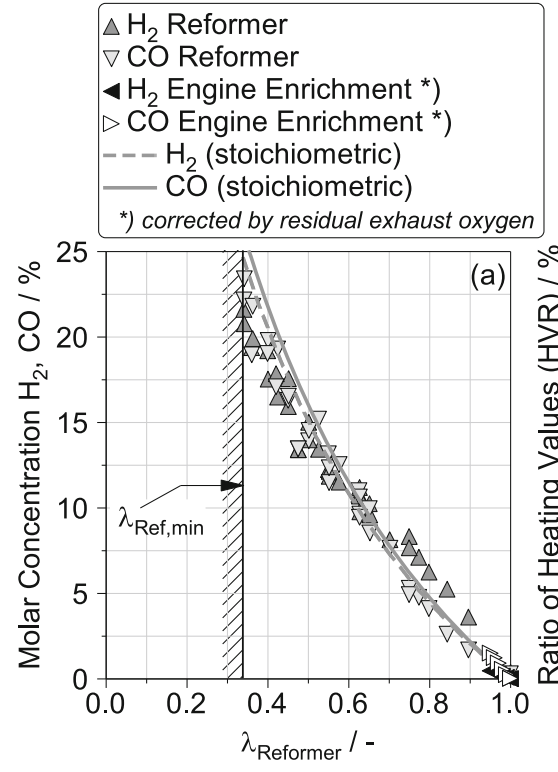

$\star \lambda_{\text {Engine }}$ of Exhaust Gas Reforming

$\triangle$ Ratio of Heating Values (HVR)

o Reductant Yield $\left(\mathrm{H}_{2}+\mathrm{CO}\right)$

Ratio of Heating Values (HVR) pure POx --- Reductant Yield $\left(\mathrm{H}_{2}+\mathrm{CO}\right)$ pure POx

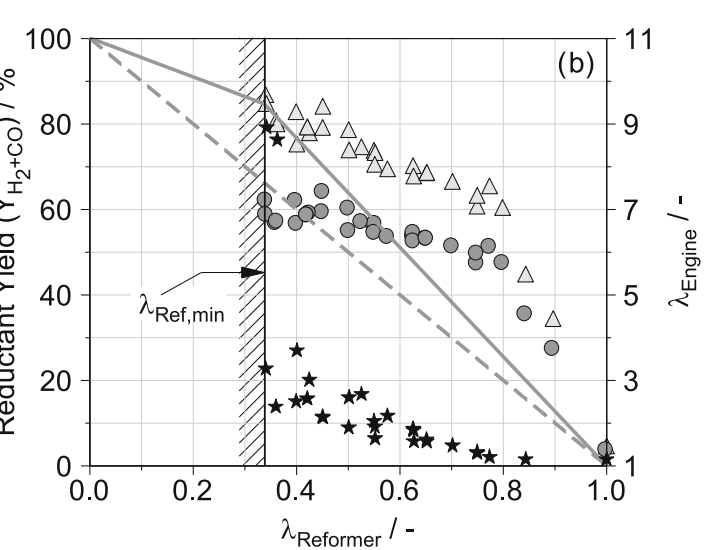

substantially higher concentrations can be achieved by the reformer. The right diagram shows a comparison of the achieved HVR as well as the reductant yield $Y_{\text {Red }}$ in contrast to corresponding theoretically attainable pure CPOx values. At lean engine operation and consequently predominantly exothermic reactant composition, due to thermal reasons, a low $\lambda_{\text {Ref }}$ must be set. Due to the high $r_{\mathrm{POx}}$ for these conditions, HVR and $Y_{\text {Red }}$ are close to the CPOx value. With decreasing engine lambda and consequently increasing endothermic reactant composition, $\lambda_{\text {Ref }}$ has, on the one hand, to be enleaned to support endothermic reaction enthalpy. On the other hand, it offers high reformate quality. In comparison to pure CPOx, exhaust gas reforming shows significant benefits for HVR and $Y_{\text {Red }}$ due to the partly conversion of thermal energy of the exothermic CPOx into chemical energy by the endothermic reactions. This helps reducing thermal stress and aging. However, HVR is reached due to partial oxidation of fuel with molecular oxygen a maximum of $85 \%$ at $\lambda_{\mathrm{Ref}}=0.35$.
Consequently, for DPF regeneration in comparison with late engine internal injection or engine external fuel injection with ideal $\mathrm{HVR}=1$, external fuel reforming does not represent an alternative.

A final comparison of the reductant yield $Y_{\text {Red }}$ for the exhaust gas fuel reformer and an engine-rich operation is shown in Fig. 9. $Y_{\text {Red }}$ for the engine operation in case of non-available measurement of all exhaust gas species is calculated by Eq. 13. The theoretical optimum reductant yield is represented by the direct use of fuel for the LNT regeneration. In this case, the reductant yield is $100 \%$. However, this approach is usually hardly practicable.

$$
Y_{\text {Red,engine }}=\frac{\dot{m}_{\text {engine fuel, rich mode }} \cdot\left(1-\lambda_{\text {engine, rich mode }}\right)}{\dot{m}_{\text {engine fuel, rich mode }}-\dot{m}_{\text {engine fuel, lean mode }}}
$$

The conventional LNT regeneration done by engine internal enrichment is mainly achieved by throttling and hence
Fig. 9 Reductant formation yield of additional fuel for LNT enrichment by fuel reforming in comparison to Diesel engine enrichment of various engine calibrations: a as function of $\mathrm{A} / \mathrm{F}$ ratio of the engine during lean operation and $\mathbf{b}$ as function of the engine's brake mean effective pressure $(B M E P)$

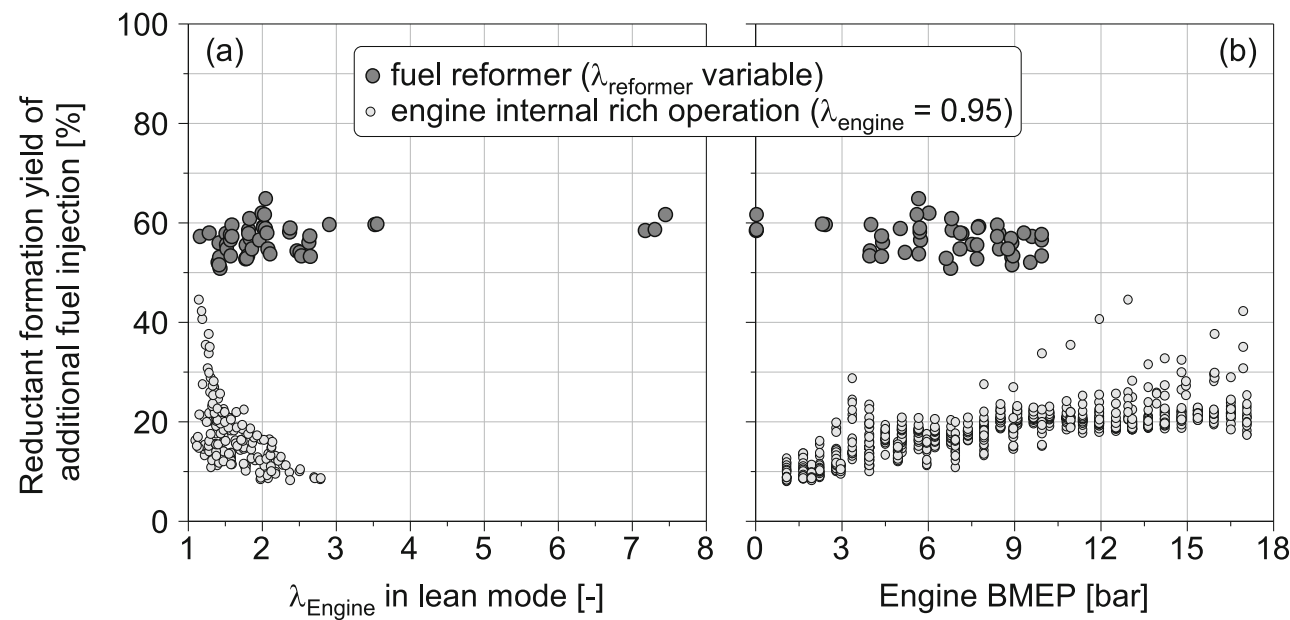


intake oxygen reduction as well as applying early and late post-injections for excess $\mathrm{HC}, \mathrm{CO}$, and $\mathrm{H}_{2}$ concentrations. However, the main portion of the additionally injected fuel is consumed for compensating combustion efficiency losses caused by engine measures to reduce the typical lean diesel air-to-fuel ratio towards $\lambda=1$. As shown in Fig. 9, only 10 $45 \%$ of the additionally expended fuel is available as reducing agent in the exhaust gas. The scatter band in Fig. 9 includes various current diesel engine calibrations. The reductant yield is slightly increasing with increasing BMEP or decreasing $A / F$ ratio during normal lean operation mode. In contrast to the diesel engine enrichment, the reductant yield of the fuel reformer reaches a significantly higher level of about $50-60 \%$, as shown in Fig. 9. The exhaust gas fuel reformer operation was optimized in terms of low HC emission and high efficiency. The reductant loss in the reformer is caused by the partial oxidation of the fuel with oxygen from lean exhaust gas or secondary air. Nevertheless, the reformer shows significantly higher efficiency in comparison to the conventional approach by engine internal-rich operation. In contrast to the enginerich operation, the reformer operation is also possible for zero engine loads (idle, overrun). The final fuel consumption penalty in the LNT system in the vehicle is strongly dependent on the LNT operation strategy and $\mathrm{NO}_{\mathrm{X}}$ emission and is described in detail in a previous paper [19].

The HC emissions are summarized in Fig. 10. The left diagram shows the $O$-equivalent $\mathrm{HC}$ share in the sum of all reductants $r_{\mathrm{HC}}, O$-equivalent $(\mathrm{Eq}$. 14) by the exhaust gas fuel reformer in comparison to diesel engine-rich operation. This parameter is based on $\mathrm{HC}$ species $\mathrm{C}_{3} \mathrm{H}_{6}$ due to calibration of the FID by $\mathrm{C}_{3} \mathrm{H}_{6}$. The right diagram shows the $C$-equivalent $\mathrm{NMHC}$ and $\mathrm{CH}_{4}$ yields (Eqs. 15 and 16) achieved under steady-state reforming conditions.

$r_{\mathrm{HC}, O \text {-equivalent }}=\frac{9 \cdot \dot{n}_{C_{3} H_{6}}}{9 \cdot \dot{n}_{C_{3} H_{6}}+\dot{n}_{H_{2}}+\dot{n}_{C O}}$

$$
\begin{aligned}
Y_{C H_{4}} & =\frac{\dot{n}_{C H_{4}}}{12.93 \cdot \dot{n}_{\text {Diesel }}} \\
Y_{N M H C} & =\frac{x \cdot \dot{n}_{N M H C_{x}}}{12.93 \cdot \dot{n}_{\text {Diesel }}}
\end{aligned}
$$

For the investigated engine-rich calibrations, the $\mathrm{HC}$ share in the reductants was $15-40 \%$ for low engine loads and up to $55 \%$ for high engine loads. The reformer shows relevant HC emissions up to $12 \%$ only during low engine loads with high $r_{\mathrm{POx}}$ and hence low $\lambda_{\text {Ref }}$ setting. The $\mathrm{HC}$ emissions are strongly dependent on $\lambda_{\text {Ref }}$ as summarized in the right diagram by $Y_{\mathrm{NMHC}}$ and $Y_{\mathrm{CH} 4}$. Above $\lambda_{\mathrm{Ref}}=0.5$, the $\mathrm{HC}$ yields are below $1 \%$. For optimized reformer control at low $\lambda_{\text {Ref }}$ close to $\lambda_{\text {Ref, }}$ min, for example at conditions with high $\lambda_{\text {Engine }}$ and hence high $r_{\mathrm{POx}}, \mathrm{HC}$ yields for $\mathrm{CH}_{4}$ and $\mathrm{NMHC}$ of 5-7 \% have been achieved.

\subsection{WGS Measurements}

In addition to the steady-state reforming investigations, the potential of a water gas shift unit positioned downstream the reformer was evaluated. The general intention is the minimization of the $\mathrm{CO}$ share in the reformate gas and increasing the $\mathrm{H}_{2}$ share due to the lower activity of $\mathrm{CO}$, for example for the LNT regeneration.

The steady-state potential of a passively operated WGS, i.e., without $\mathrm{H}_{2} \mathrm{O}$ dosing, is strongly dependent on the reforming conditions, especially on the $\mathrm{H}_{2} \mathrm{O}$ concentration in the reformate gas. For high $\lambda_{\text {Engine }}$ and hence high $r_{\mathrm{POx}}$, the $\mathrm{H}_{2} \mathrm{O}$ concentration in the reformate gas is very low. Under these conditions, almost no WGS is possible. With decreasing $r_{\text {POx }}$ and increasing $\mathrm{H}_{2} \mathrm{O}$ concentration, steady-state WGS potential increases and reaches theoretically, for example $85 \%$ at $r_{\mathrm{POx}}=0.45$ ( $85 \%$ of $\mathrm{CO}$ after the reforming can be shifted to $\mathrm{H}_{2}, 82 \%$ were measured). For transient operation conditions, for example in an after treatment application, the $\mathrm{Pt} / \mathrm{CeO}_{2}$ based WGS shows further disadvantage. During reforming
Fig. $10 \mathrm{HC}$ emissions in rich feed gas for LNT regeneration by fuel reforming in comparison to diesel engine enrichment of various engine calibrations: a $O$ equivalent $\mathrm{HC}$ share in total reductants as function of the engine's brake mean effective pressure $(B M E P)$. b NMHC and $\mathrm{CH}_{4}$ yield as function of $\lambda_{\mathrm{Ref}}$
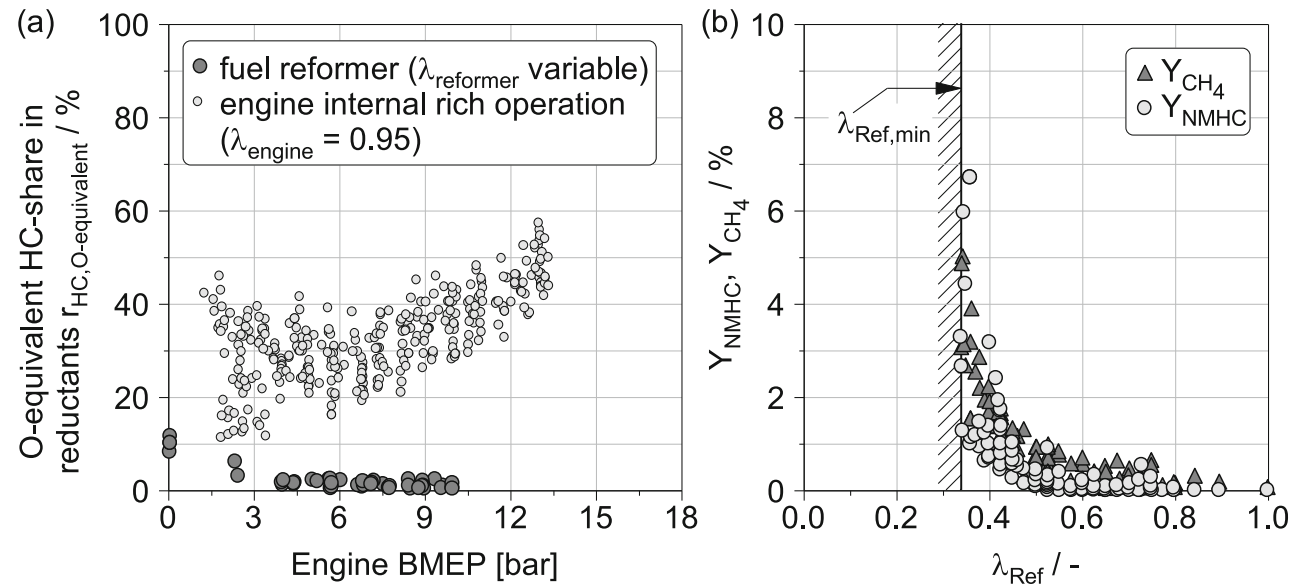
start, $\mathrm{H}_{2}$ and $\mathrm{CO}$ get converted to $\mathrm{H}_{2} \mathrm{O}$ and $\mathrm{CO}_{2}$ by reducing the oxygen storage of WGS (due to $\mathrm{CeO}_{2}$ ). This represents a considerable loss in the overall efficiency. On the opposite side, one advantage of this oxygen function on the WGS could be the conversion of a potential HC peak in the reformate gas during reformer start.

\section{Summary and Conclusions}

For the application area of LNT operation as part of a diesel exhaust after treatment system, a fuel reformer was designed and theoretically and experimentally investigated. As the most suitable design, a coaxial design with a ring-shaped reformer catalyst was chosen. The reformer is positioned outline to enable a very flexible reformer operation. The fuel reforming concept is predominantly based on engine exhaust gas to avoid complex system architectures and to take advantage of the "free of charge" existing exhaust gas.

By the theoretical and experimental investigations, the strong dependence of the reformer operation on the exhaust gas condition, i.e., of the $\mathrm{O}_{2}, \mathrm{H}_{2} \mathrm{O}$, and $\mathrm{CO}_{2}$ concentrations, could be demonstrated. With steady-state measurements, optimum reformer control settings could be defined in order to find both high system efficiency and low HC slip. In comparison to pure CPOx, exhaust gas reforming shows high benefits in terms of efficiency and thermal behavior, especially with regard to the critical maximum temperature. It is caused by partly conversion of thermal energy of the exothermic CPOx into chemical energy by the endothermic reforming reactions. This helps reducing thermal stress and aging.

In comparison to conventional engine-rich operation for LNT regeneration, the reformer shows significant advantages in terms of system efficiency and $\mathrm{HC}$ share in the reductants. With the reformer, a reductant yield of above $50 \%$ could be achieved, whereas the engine-rich operation shows 10-25\% up to medium engine load and up to $45 \%$ for high engine load.

A passively operated water gas shift unit, i.e., without secondary $\mathrm{H}_{2} \mathrm{O}$ supply, positioned downstream the reformer was experimentally tested to reduce the $\mathrm{CO}$ share in the reformate gas. However, a WGS benefit could only be achieved for low $\lambda_{\text {Engine }}$ with thereupon high $\mathrm{H}_{2} \mathrm{O}$ concentrations in the reformate gas. In transient operation with discontinuous lean and rich operation, the WGS is not suitable due to reformate oxidation by the oxygen storage capacity.

Summarizing, the outline positioned, coaxial designed exhaust gas reforming concept shows beneficial performance in steady-state operation. However, highly transient operation in a vehicle and especially the system cold start need to be further investigated and optimized.
Acknowledgments The research leading to these results has received funding from the European Union 7th Framework Program [FP7/20072011] under grant agreement No. 234032. The authors are grateful to the funding of EU in the POWERFUL research project and all persons, who know to have their contribution in this study.

Furthermore, the authors would like to thank the $D F G$ for enabling this work by funding the mass spectrometer measurement devices.

Parts of this work are the result of the successful cooperation with RWTH's Center for Automotive Catalytic Systems Aachen (ACA).

\section{References}

1. Tully, E.J., Heywood, J.B.: Lean-burn characteristics of a gasoline engine enriched with hydrogen from a plasmatron fuel reformer. SAE 2003-01-0630 (2003)

2. Quader, A.A., Kirwan, J.E., Grieve, M.J. : Engine performance and emissions near the dilute limit with hydrogen enrichment using an on-board reforming strategy. SAE 2003-01-1356

3. Conte, E., Boulouchos, K.: Influence of hydrogen-rich-gas addition on combustion, pollutant formation and efficiency of an IC-SI engine. SAE 2004-01-0972 (2004)

4. Topinka, J.A., Gerty, M.D., Heywood, J.B., Keck, J.C.: Knock behaviour of a lean-burn, $\mathrm{H}_{2}$ and $\mathrm{CO}$ enhanced, SI gasoline engine concept. SAE 2004-01-0975 (2004)

5. Allgeier, T., Klenk, M., Landenfeld, T., Conte, E., Boulouchos, K., Czerwinski, J.: Advanced emission and fuel economy concept using combined injection of gasoline and hydrogen in SI-engines. SAE 2004-01-1270 (2004)

6. Tsolakis, A., Megaritis, A.: Exhaust gas fuel reforming for diesel engines - a way to reduce smoke and NOx emissions simultaneously. SAE 2004-01-1844 (2004)

7. McWilliam, L., Megaritis, T., Zhao, H.: Experimental investigation of the effects of combined hydrogen and diesel combustion on the emissions of a HSDI diesel engine. SAE 2008-01-1787 (2008)

8. Tsolakis, A., Megaritis, A., Yap, D., Abu-Jrai, A.: Combustion characteristics and exhaust gas emissions of a diesel engine supplied with reformed EGR. SAE 2005-01-2087 (2005)

9. Bromberg, L., Crane, S., Rabinovich, A., Heywood, J.B., Alexeev, N., Samokhin, A.: Hydrogen generation from plasmatron reformers: a promising technology for NOx adsorber regeneration and other automotive applications. Paper presented at the Diesel Engine Emission Reduction (DEER) Workshop, Newport, 24-28 August (2003)

10. Kong, Y., Crane, S., Patel, P., Taylor, B.: NOx trap regeneration with an on-board hydrogen generation device. SAE 2004-01-0582 (2004)

11. Hu, H., Reuter, J., Yan, J., McCarthy, J.: Advanced NOx after treatment system and controls for on-highway heavy duty diesel engines. SAE 2006-01-3552 (2006)

12. Khadiya, N., Cranen S., Huffmeyer, C., Taylor, B.: A fast start-up on-board diesel fuel reformer for NOx trap regeneration and desulfation. SAE 2004-01-2684 (2004)

13. Kupe, J., Zizelman, J., Botti, J.J., Simpkins, H., Hemingway. M.D., LaBarge, W.J., Silvis, T.W., Kirwan, J.E., Bonadies, J., Price, K.: System and method of NOx abatement. Delphi Technologies Inc. Patent US 2006/0213187 A1, 28 September (2006)

14. Hemingway, M.D., Christopher, B.J., Thornton, M.P.: Engine exhaust emission control system providing on-board ammonia generation. Delphi Technologies Inc. Patent US 2007/0271908 A1, 29 November 2007

15. Kupe, J., Bosch, R., Bonadies, J., Kirwan, J.: Demonstration of a fuel reformer system for meeting future diesel vehicle low emission standards. Paper presented at the 15th Aachen Colloquium 
Automobile and Engine Technology, RWTH Aachen University, Aachen, 9-11 October 2006

16. McCarthy, J.: Fuel reformer, LNT and SCR aftertreatment system meeting emissions useful life requirements. Paper presented at the Directions in Engine-Efficiency and Emissions Research (DEER) Conference, Dearborn, 3-6 August 2009

17. Poojary, D., Nicole, J., McCarthy, J., Yang, H.: Improved system performance and reduced COST of a fuel reformer, LNT, and SCR aftertreatment system meeting emissions useful life requirement. Paper presented at the Directions in Engine-Efficiency and Emissions Research (DEER) Conference, Detroit, 27-30 September 2010

18. McCarthy, J., Yue, Y., Mahakul, B., Gui, X., Yang, H., Ngan, E., Price, K.: Meeting nonroad final tier 4 emissions on a 4045 John Deere engine using a fuel reformer and LNT system with an optional SCR showing transparent vehicle operation, vehicle packaging and compliance to end-of-life emissions. SAE 2011-01-2206 (2011)

19. Wittka, T., Holderbaum, B., Dittmann, P., Pischinger, S.: Experimental investigation of combined LNT + SCR diesel exhaust aftertreatment. Emission Control Science and Technology 2 (2015). doi:10.1007/s40825-015-0012-0
20. Shekhawat, D., Spivey, J., Berry, D.: Fuel Cells: Technologies for Fuel Processing. Elsevier (2011)

21. Hartmann, L., Lucka, K., Köhne, H.: Mixture preparation by cool flames for diesel-reforming technologies. J. Power Sources 118, 286-297 (2003)

22. Bonadies, J.V., Goulette, D.A., Kirwan, J.E., Seino, M.J., Kupe, J. Bosch, R.H. (2006) Application of a diesel fuel reformer for tier 2 bin 5 emissions. Paper presented at U.S. Department of Energy DEER Conference

23. Neels, J., Li, X., Sederquist, R.A., Boulet, A., Logan, W.A.: Compact fuel reformer. Nxtgen Emission Controls Inc. Patent WO 2008/131562 A1, 06 November (2008)

24. Maus, F.: $\mathrm{CO} / \mathrm{H}_{2}$-Synthesegaserzeugung durch Benzinreformierung und Benzin/Reformat-Mischbetrieb von Otto-Motoren. PhD Thesis University of Stuttgart (2008)

25. Outokumpu HSC Chemistry ${ }^{\circledR} 4.0$ Chemical Reaction and Equilibrium Software. (1999)

26. Amphlett, J., Mann, R., Peppley, B., Roberge, P., Rodrigues, A., Salvador, J.: Simulation of a $250 \mathrm{~kW}$ diesel fuel processor/PEM fuel cell system. J. Power Sources 71, 179-184 (1998)

27. Daubert, T.E., Danner, R.P.: Physical and thermodynamic properties of pure chemicals 